\title{
A New Hybrid Bathroom System Based on Energy Saving Concept
}

\author{
Bo-wen Cui \\ Shandong University of Science and Technology, Mining and Safety engineering institute,ShanDong, QingDao,266590)
}

\begin{abstract}
Based on the characteristics of hot water supply in bathroom, this article proposes a new hybrid energy hot water supply system. The programmable logic controller(PLC) as the master controller was adopted in this system, which could automatically detect and storage main thermal physical of the system, such as temperature, water level, solar radiation intensity, power consumption and so on. The active thermal utilization technology of solar energy, air-source heat pump technology, solar energy intensive natural ventilation technology and low temperature hot water floor radiant heating technology were organically integrated in this system, which has the advantages of energy conservation and environment protection, high automation, safe and reliable operation, etc. At the same time, it can make good use of electric power cost between on-peak and off-peak, and promote the optimal allocation of power resources and reduce the cost, which can achieve the goal of intelligent control and energy saving.
\end{abstract}

\section{Introduction}

With the continuous improvement of living standards, people's demand for quality is also getting higher and higher, in order to relax and shape a good personal image, bath has become an indispensable activity in people's lives. Comfortable bath can ease the pressure, can provide a stable supply of hot water and a good heating and ventilation system is an important guarantee for the realization of the bathroom. At present, the solar hot water supply technology is becoming more and more mature, has been widely used, but it is highly dependent on environmental conditions, the stability and reliability is poor, often need to combine with the stable heat source. Boiler hot water supply system combustion of coal and other fossil fuels, emissions of $\mathrm{SO} 2, \mathrm{CO} 2$ and other waste gas, serious pollution and energy consumption. The traditional bathroom heating system usually use gas or coal boiler as heat source, rely on the installed on the wall of the indoor heating radiator heating device. The heating efficiency of the bathroom heating system is relatively low, and the heated air is concentrated in the upper part of the room, and the discomfort of the head and the feet is cool. In addition, most of the traditional bathroom adopt simple natural ventilation technology and its effect is poor, lead to indoor air pollution, hypoxia and make people feel serious discomfort.

In this article, we come up a heat pump water heater ${ }^{[1]}$, which drived by motor, use the vapor compression refrigeration cycle with air as the heat source and provide hot water. In the system we combine solar energy utilization technology and heat pump technology for hot water supply[2], which can bring into full play to the advantages of energy conservation and achieve all weather reliable operation of the system. In recent years, low-temperature floor radiant heating system is a new heating type, it takes the whole ground as a heat sink, when convective heat transfered between floor and indoor air, people can have a comfortable feeling- feet warm head cool, then it can use the low-grade heat source as heat source, it is a kind of ideal heating system to reduce the energy consumption and improve the comfort of the building.

In part 1, we introduce the composition of hybrid energy-saving bathroom system; In part 2 we introduce the working principle and performance analysis of the system; In part 3 we introduce the innovation and application in other fields.

\section{Composition of Hybrid Energy-saving}

\section{Bathroom System}

Aiming at the fixed opening time, large water consumption, stable discharge temperature and moderate washing temperature in colleges and enterprises, we construct a new hybrid energy-saving bathroom system, which comprises a solar assisted air-source heat pump hot water subsystem, a low temperature hot water floor radiant heating subsystem and a solar energy intensive natural ventilation subsystem. Solar assisted air-source heat pump hot water subsystem ${ }^{[3]}$ consisted the plate type solar heat collector, heat exchanger, heat storage tank, 
circulating water pump and other components; Air-source heat pump unit, heat storage water tank, circulating water pump and other parts constitute air-source heat pump system. Low temperature hot water floor radiant heating system constituted by the air-source heat pump, thermal storage tank, circulating water pump and a heating coil. The solar energy intensive natural ventilation system composed by a transparent cover plate, an air channel, a heat absorbing plate, a heating accumulator and an insulating board.

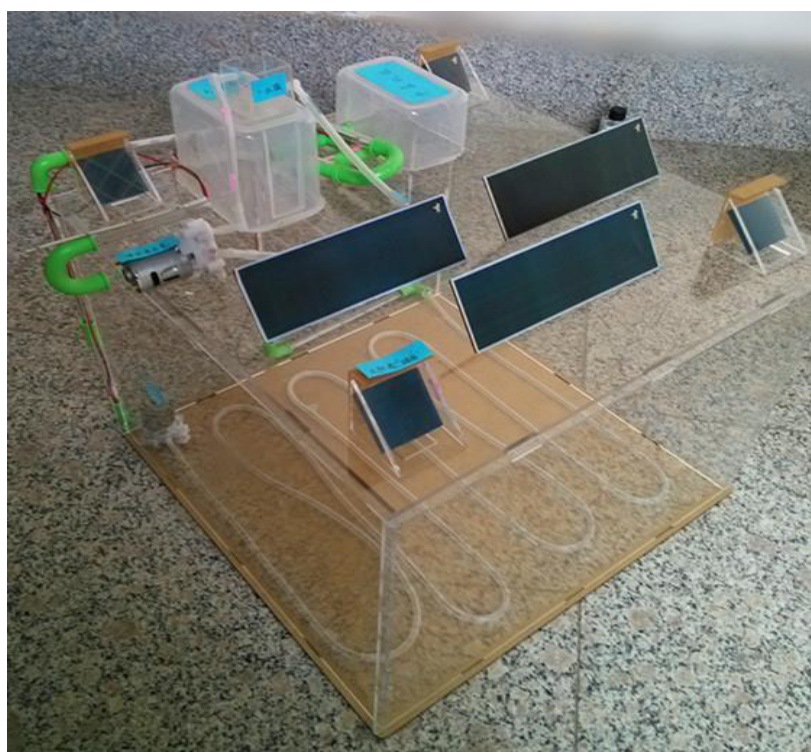

Figure 1. The system model in physical map

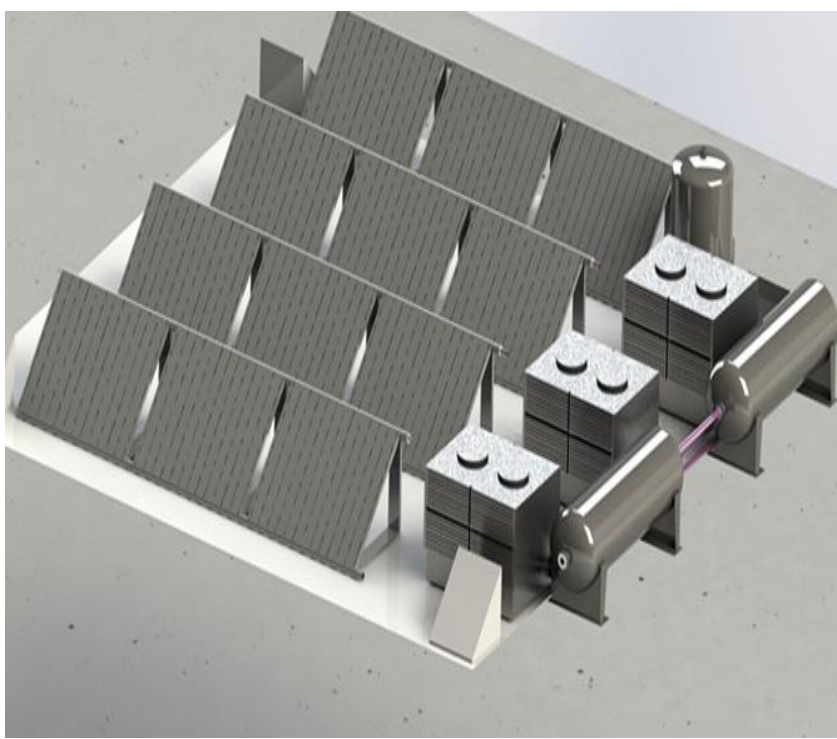

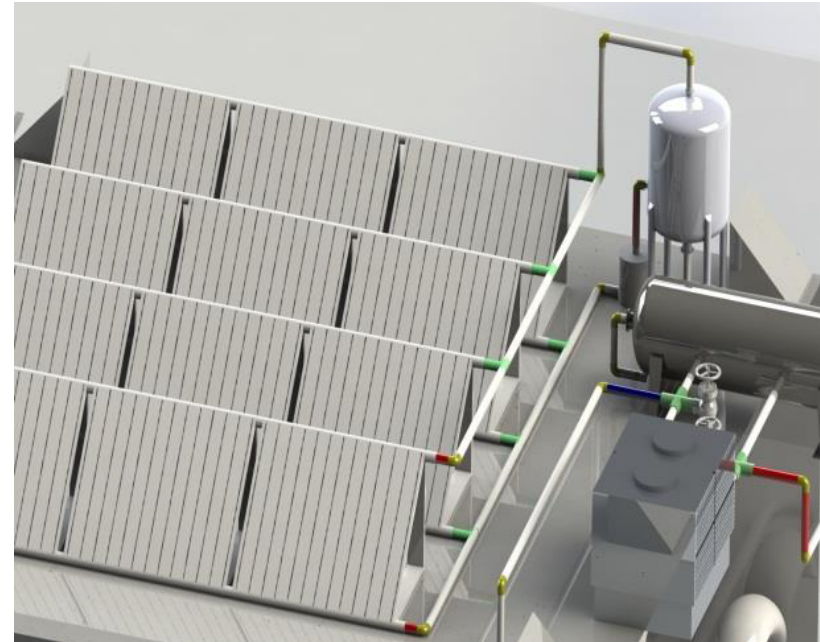

Figure 2. The solar energy, air source heat pump system

\section{Working Principle and Performance}

\section{Analysis of the System}

\subsection{Hot water heating system}

Aiming at the characteristics of the solar collector's large area and low energy conversion rate, the system adopts the combination of air-source heat pump system and the solar heat collection as a supplement[4]. In order to prevent freezing in winter, the working medium in solar collector subsystem is selected as propylene glycol solution, transfered the collected heat to the storage tank through heat exchanger. The system operated by temperature cycle control mode, using two temperature sensors and one temperature controller, one of the temperature sensor is installed in the heat collector, which is close to the outlet of propylene glycol, the other installed in the storage tank bottom near the outlet. The circulating water pump started when the temperature of the propanediol is higher than the heat storage water tank and the temperature difference controller achieved the starting temperature difference. When the difference is lower than the temperature controller set, the water pump will stop running, repeatedly like this, the water temperature in the heat storage tank is increasing continuously. In the setting time, if the temperature of the heat storage water tank can't reach the set, which the bath water supply, the electromagnetic valve will be opened, and the air source heat pump unit is auxiliary heating.

The air-source heat pump heating subsystem use heat storage water tank temperature control mode, when the heat storage water tank water temperature is lower than the temperature of water bath start followed by the circulating water pump and the heat pump unit, until the water temperature in the water tank reaches the set value, and then turn to stop heat pump unit and a water circulating pump. When the outdoor temperature in winter is very low, air source heat pump heating efficiency is greatly reduced, and at the set time of insufficient heat. At this point the system by thermal power plant auxiliary steam heating mode of operation, to open the solenoid 
valve until two heat storage water temperature in the water tank reaches the set temperature of bath water. Combined with the state of peak and valley electricity policy, the heat pump can be in the off peak period (23:00 - 7:00 the next day) run, this will not only ease the peak power demand and supply gap, and promote the optimal allocation of power resources, is a "cut peak and fill valley" win-win strategy.

\subsection{Bathroom heating system}

Beforethe period when people use their bathroom, namely at the off-peak period, the running air-sourceheat pump heats th heat storage water tank for floor heating, and when the temperature of water reach the limit, the air-source-heat pump shuts down. When it needs heat, hot water circulating pump is switched on. The hot water in the heat storage water tank is transported into the floor heating coil, heating the floor in the bathroom and the space above the floor by radiation and convection and then returning to the heat storage water tank. When the temperature of the hot water hit the floor level, the air-source heat pump is switched on.

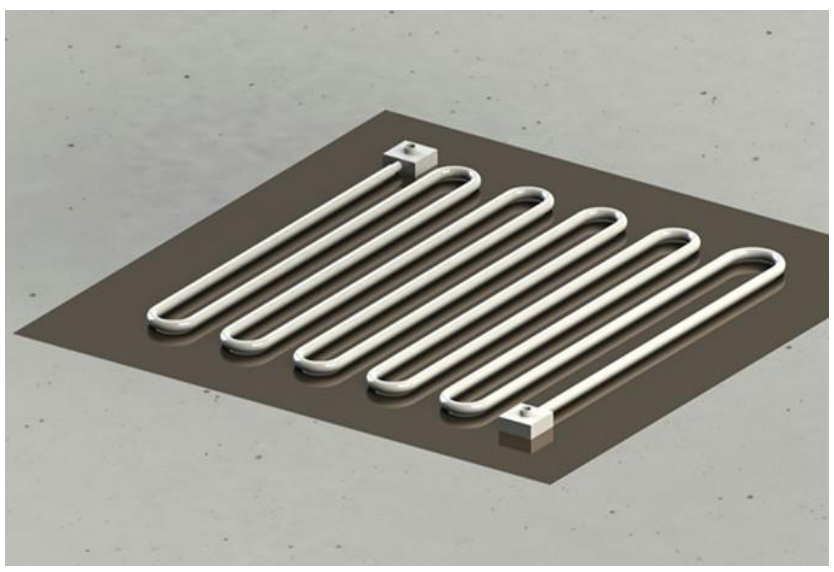

Figure 3. The heating coil diagram

\subsection{Bathroom ventilation system}

During the daytime, the sunshine penetrates the transparent glass cover with radiation from it absorbed by absorber plate, heating the gas in the air pipes, producing the temperature difference between the inside and the outside of the air pipes and resultant larger hot-pressure. Then the gas is flowing up along the pipes, thus the air in the bathroom is pushed into the air pipes through air outlet. The outdoor fresh air flows into the indoor space through air inlet, thus strengthening the indoor air ventilation and in the same time, the remaining part is stored in the heat storage plate for repeating the circulation in the evening
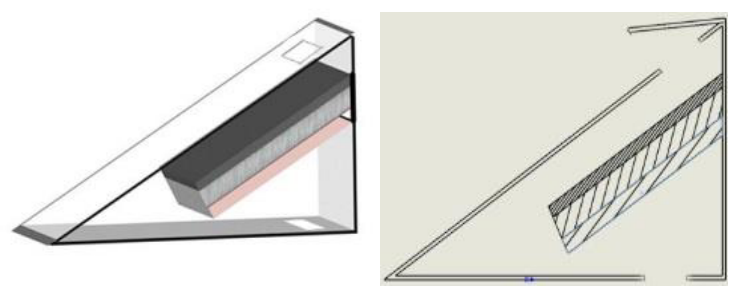

Figure 4. The solar ventilation system

\section{Innovation and Application}

(1) The hot water subsystem uses air-source heat pump system as main method and solar energy collection is supplemented by the hot water supply;

(2) The system uses the off-peak period to heat, promoted the electric power resources optimized disposition, which is a " peak load shifting " double-wins strategy;

(3)By using the solar energy and the solar radiation to heat the air, the system can strengthen natural ventilation technology and produce differential pressure to strengthen the natural ventilation cycle, which will provide comfort and the effective use of solar energy resources.

\section{Reference:}

1. Kong Xiangqiang,An Peng,Liu Xiaoxiao,Li Xinling,Li Ying. Development of Experimental Platform with Hybrid Energy Hot Water Supply System for College Bathrooms [P]. National utility model patent, ZL 201220300696.6. 2012.

2. Yang Lei, Zhang Xiaosong. Performance simulation of multiple heat source solar heat pump water heater system[J]. Acta Energiae Solaris Sinica,2011,32(1):120-126.

3. Tie Yan, Luo Huilong. Techno-economic analysis of solar water heating system in conjunction with air-source heat pump $[\mathrm{J}]$. refrigeration and air-conditioning,2009,9(4):31-32

4. Yuan Jianshan, Zhang Guangshun, Zhang Jinfeng. Handbook of solar water heating systems [M].Beijing: Chemical Industry Press,2010. 